\title{
"I just have diabetes": children's need for diabetes self-management support and how a social robot can accommodate their needs
}

This article was published in the following Dove Press journal:

Patient Intelligence

13 July 2012

Number of times this article has been viewed

\author{
Olivier A Blanson \\ Henkemans \\ Vera Hoondert \\ Femke Schrama-Groot \\ Rosemarijn Looije \\ Laurence L Alpay \\ Mark A Neerincx \\ TNO, Lifestyle, Leiden, \\ The Netherlands
}

Correspondence: Olivier A Blanson Henkemans

TNO, Wassenaarseweg, 56, $2333 \mathrm{AL}$,

Leiden, The Netherlands

$\mathrm{Tel}+3 \mid 0888666186$

Fax +310715181918

Email olivier.blansonhenkemans@tno.nl
Purpose: Children with type 1 diabetes need to self-manage their illness to minimize its impact on their long-term health. However, because children are still developing cognitively and emotionally, self-management is challenging. The European FP7 project, ALIZ-E, looks at how social robots can support children aged 8-12 years with their diabetes self-management. To acquire user requirements for such a robot, we studied how diabetes self-management is organized for children and how they experience their illness and its management regarding their quality of life.

Methods: We conducted semistructured interviews with diabetes caregivers $(n=6)$ and children $8-12$ with type 1 diabetes $(n=9)$, and surveyed their parents $(n=9)$.

Results: Results of the interviews with caregivers show that parents play a prominent role in diabetes self-management and, accordingly, children do not experience significant problems. However, because children develop a need for autonomy during puberty, it is important that they become more proficient in their self-management at an earlier age. Results of the interviews with children show that they accept diabetes as a part of their life and want to be seen as regular children. Also, children experience difficulties in unusual situations (eg, doing sports and vacationing) and at school. The illness comes at the cost of the child's mental wellbeing (eg, insecurity, fear, and worry) and physical well-being (eg, listlessness and tiredness). Regarding social well-being, children enjoy attending diabetes camps and having friends with diabetes, due to a common understanding of their condition. Finally, parents are not always fully aware of how children experience their illness.

Conclusion: Children could benefit from social robots offering motivation, training, and (parental) monitoring and support, and serving as a fallback for uncommon events. To prevent stigmatization, the robot would need to act as a buddy and not as a support tool in the management of diabetes.

Keywords: chronic illness, coping, child-participation, social robot, personalized support

\section{Introduction}

Children aged 4-12 years with type 1 diabetes need to perform self-management throughout the day to minimize the impact of their illness on their short-term and long-term health. Self-management is positively associated with metabolic control ${ }^{1-4}$ and health-related quality of life..$^{5-8}$ It consists of monitoring carbohydrate intake, physical activity, and blood glucose, recognizing symptoms of hypoglycemia and hyperglycemia, and pricking insulin to regulate blood glucose levels accordingly. In short, these children, comprising approximately 480,000 worldwide, ${ }^{9}$ are diabetes experts. 
Self-management knowledge and skills are developed as children grow older, and self-management performance improves accordingly. However, at this age, the children are still developing emotionally and cognitively, and diabetes self-management is complex. Thus, they are not always able to apply their expertise optimally. Activities such as making calculations (required to administer the correct amount of insulin) or dealing with low glucose levels in unfamiliar situations can be challenging. Moreover, in order to maintain a good quality of life, they will aim at acquiring a balance between self-management activities and experiences in important life domains, such as school and social life. ${ }^{10}$ In turn, from a medical view, this may lead to mismanagement of diabetes. ${ }^{11}$

\section{ALIZ-E: personalized long-term child-robot interaction}

The European 7th framework (FP7) project ALIZ-E is studying how social robots can help the children to cope with the situated self-management needs, through personalized, adaptive and long-term interaction. A study of Latitude showed that children can rather easily imagine learning environments that incorporate robots. ${ }^{12}$ In total, 350 children aged 8-12 years were asked to select and write a story around one of three narrative prompts rooted in specific life settings: in the classroom; at school, but outside of class; and at home after school. Other research showed that interacting with personal computer assistants, such as social robots, can contribute to self-management. Janssen et al studied the effects in children aged 9-10 years who interacted with a social robot versus a nonsocial robot, over a period of a week, regarding health awareness, use of a diary, and performing exercise. ${ }^{13}$ The social robot showed interest in the user (eg, remembered his/her name) and showed social behavior at appropriate moments (eg, was motivating when necessary). The results showed that both robots were motivating and fun to use, but the social robot was a better educator and invoked more engagement. Furthermore, the children experienced the social robot as being more empathetic.

Blanson Henkemans et al studied the effect of a personal computer assistant on the use of an online lifestyle diary, regarding diet and exercise, by adults who were overweight. ${ }^{14}$ The computer assistant was integrated into the diary and facilitated setting personal health goals and provided motivating feedback. Over a period of 4 weeks, participants with the computer assistant experienced the diary as more userfriendly, were more motivated to perform self-management, and attained a healthier body mass index.
These studies provide a good starting point for developing a social robot that provides dedicated support for children with type 1 diabetes. To meet the support needs of this specific user group, we first have to analyze how diabetes self-management is organized for these children and how the children experience their illness and its management in regard to their quality of life. Subsequently, based on this analysis, we can derive user requirements and robot functionalities for situated self-management support of diabetic children.

Earlier research on the experience of children with their diabetes and self-management has been mainly conducted from a caregiver's point of view. ${ }^{15}$ It showed that there is a mismatch between what scientists and clinicians believe is the best way to manage type 1 diabetes and the actual capabilities and preferences of children with diabetes and their parents with regard to managing the illness. ${ }^{2}$ Therefore, to answer our research questions, we conducted semistructured interviews with both diabetes care providers, children with type 1 diabetes, and their parents. This article discusses the methods used and results of the interviews with the care providers and the children. Finally, it discusses the implications of these results for the development of a social robot for children with diabetes.

\section{Materials and methods}

\section{Participants and recruitment procedure}

In July 2010, we approached 12 Dutch hospitals and medical centers to recruit diabetes health care personnel (ie, diabetes nurse, a pediatrician, dietician, and psychologist) for our study. The hospitals and medical centers all had a pediatrics and/or diabetes clinic. After receiving an introduction to our study by phone and subsequently an information letter, five hospitals and medical centers (ie, Martini Ziekenhuis, Deventer Ziekenhuis, Medisch Spectrum Twente, Diabeter, and Kinder Diabetes Centrum Nijmegen) referred us to their diabetes health care personnel to interview.

Six care providers agreed to participate in our study, ie, two children's diabetes nurses, a diabetes nurse, a pediatrician, a psychologist, and a dietician. Interviews with these professionals were held on location. Interviews lasted approximately 60 minutes and were recorded using a portable digital recorder.

In September 2010, we approached 11 Dutch hospitals and medical centers and one diabetes patient association to recruit children with diabetes for our study. The hospitals and medical centers all had a pediatrics or diabetes clinic. A hospital and medical center (ie, Franciscus Ziekenhuis Roosendaal and Diabeter) sent an information and invitation letter to the parents of their young patients. 
Nine parents responded to the invitational letter and agreed to have their children interviewed. We interviewed three boys and six girls. As listed in Table 1, at the time of the interview, their median age was 10 (interquartile range [IQR] 3) years, the median number of years they had diabetes was 4 (IQR 2), and their median glycosylated $\left(\mathrm{HbA}_{1 \mathrm{c}}\right)$ value was 7 (IQR 2.2). Seven children used an insulin pump and two injected insulin. None of the children was multimorbid. Five children were treated at a hospital with a pediatric diabetes department and four children were treated at a medical institution specializing in pediatric diabetes. Eight children lived in a two-parent home and had at least one sibling. The interviews with the children took place at home. Interviews lasted approximately 45 minutes and were recorded using a portable digital recorder. The parents filled in a survey while their child was being interviewed.

\section{Interview topics}

The semistructured interviews with the caregivers were based on the Work Innovation Measurement Tool. ${ }^{16}$ This tool is used to assess how work processes can be innovated and enables insights in the current situation and provides directions for improvements. Three types of data are assessed, ie, work processes and involved actors, task performance of involved actors and required task time, and quality evaluation and implications for future directions. For our study, we used this tool to assess the organization of self-management for the involved actors (ie, professionals, children, and parents), the tasks performed, and how self-management is evaluated. Table 2 lists the topics and underlying subjects discussed with the caregivers.

The interviews with the children were based on the MIND Youth Questionnaire ${ }^{17}$ and the Child Health Questionnaire. ${ }^{18}$ The MIND Youth Questionnaire consists of different validated questionnaires, ie, the Pediatric Quality of Life Inventory, the Diabetes Family Conflict Scale, the Confidence in Diabetes Self-Care-Youth, and questionnaires about mismanagement. The MIND Youth Questionnaire covers the following

Table I Demographics and medical background of interviewed children $(n=9)$

\begin{tabular}{ll}
\hline Median age (interquartile range) & I0 (3) \\
Gender (male/female) & $3 / 6$ \\
Median years diabetes mellitus type I & $4(2)$ years \\
(interquartile range) & \\
Median HbA Ic $_{\text {value (interquartile range) }}$ & $7(2.2) \mathrm{mmol} / \mathrm{L}$ \\
Using a pump & 7 \\
Treated by a hospital with a pediatric diabetes clinic & 5 \\
Treated by a medical institution specialized in pediatric & 4 \\
diabetes & \\
\hline
\end{tabular}

Table 2 Topics and underlying subjects discussed during interviews with diabetes care providers

\begin{tabular}{ll}
\hline Topic & Underlying subject \\
\hline $\begin{array}{l}\text { Self-management } \\
\text { organization } \\
\text { Tasks performed and }\end{array}$ & Work processes and involved actors \\
their effect on & $\begin{array}{l}\text { Teaching (knowledge), training (skills), } \\
\text { motivational interviewing (motivation), and }\end{array}$ \\
self-management & $\begin{array}{l}\text { personal characteristics of those influencing } \\
\text { self-management }\end{array}$ \\
$\begin{array}{l}\text { Quality evaluation } \\
\text { of self-management }\end{array}$ & $\begin{array}{l}\text { Future directions for improvement of self- } \\
\text { management }\end{array}$ \\
\hline
\end{tabular}

domains: overall quality of life, mental health (emotional well-being and worries), social life (family, parents, school, friends, and sports), diabetes management (feeling in control, treatment satisfaction, and burden) and the domain of body and weight. Because the MIND Youth Questionnaire does not cover emotional well-being and depressive symptoms, we added the WHO-Five-Well-being Index (WHO-5) survey questions addressing these two items.

The Child Health Questionnaire is a validated instrument which surveys aspects of the health of children with diabetes. It covers physical (physical functioning, general health, role/ social limitations-physical and bodily pain), psychosocial (role/ social limitations-emotional, role/social limitations-behavioral, mental health, and self-esteem), and family items (family activities and family cohesion). Table 3 lists the topics and underlying subjects discussed with the children with diabetes.

The survey we administered to the parents contained ten questions on their views about their child's diabetes self-management and its effect on their mental, social, and physical well-being. Answers were provided on a three-point scale, ie, positive, neutral, or negative. These questions corresponded to the questions posed during the

Table 3 Topics and underlying subjects discussed during interviews with children having diabetes

\begin{tabular}{ll}
\hline Topic & Underlying subject \\
\hline Diabetes self-management & $\begin{array}{l}\text { Feeling in control, acceptance of the } \\
\text { disease, knowledge about diabetes and } \\
\text { treatment satisfaction }\end{array}$ \\
Diabetes self-management & $\begin{array}{l}\text { Sport, hobbies, and activities with family } \\
\text { and friends } \\
\text { and important life domains } \\
\text { Social well-being }\end{array}$ \\
& $\begin{array}{l}\text { Contact with and support from } \\
\text { parents, siblings, friends with diabetes, } \\
\text { classmates, and school }\end{array}$ \\
Physical well-being & $\begin{array}{l}\text { Symptoms during high and low glucose } \\
\text { levels }\end{array}$ \\
Mental well-being & $\begin{array}{l}\text { Emotional well-being, worries, and } \\
\text { self-esteem }\end{array}$ \\
School & Teachers, class mates, and complications
\end{tabular}


semistructured interviews with the child. The survey also covered their child's demographic and medical data.

\section{Data analysis}

The interviews with both caregivers and children were recorded and transcribed verbatim. Following the interview, the results were coded in Excel by three authors (FG, VH, $\mathrm{OBH}$ ) along three levels, ie, interview topic, subjects within these topics, and categories within the subject.

These topics and subjects stem from the domains and items in the Work Innovation Measurement Too ${ }^{15}$ (formal care providers), the MIND Youth Questionnaire, ${ }^{17}$ and the Child Health Questionnaire $^{18}$ (children). The categories are derived from examples the interviewed caregivers and children provided within these topics and subjects. For instance, when discussing if a child feels in control of their diabetes, structuring took place, bottom-up, as: category, ie, an unexpected situation occurring, eg, hyperglycemic attack; subject, ie, feeling in control of illness; and topic, ie, diabetes self-management.

Subsequently, the responses were labeled as positive, negative, or neutral, at the subject level. For example, if the child reported that he or she knew how to handle an unexpected situation, this was labeled as positive. Categories were used to collect practical illustrations of when children had a positive, negative, or neutral experience regarding a specific subject. Finally, if an interviewee's response could not be placed within the proposed subject list, we added this as a new subject within a relevant topic.

The parents' survey results were also entered in Excel. The survey items and corresponding children's interview categories were matched. For example, the survey asked if the parents perceived their child as worrying about their diabetes, which corresponds with the child's response to the item "Worries about your diabetes". This enabled comparison of the children's actual experience of diabetes management and the parents' perception of the child's experience (ie, positive, neutral, or negative). A consistency check was conducted on the results of the two coders. There were no inconsistencies, except for the topic related to diabetes management and school (ie, the coders placed the category school under different topics). Accordingly, school was added as a separate topic.

\section{Results}

\section{Diabetes self-management} Becoming a diabetes expert

The interviewed care providers reported that in order to self-manage their illness effectively, children need to become diabetes experts. This implies accepting their illness, developing the necessary skills to monitor their blood glucose levels, count their carbohydrate intake, determine how much and which insulin to inject, cope with unusual occasions, and recognize symptoms of hypoglycemia (low blood sugar) and hyperglycemia (high blood sugar). Moreover, it implies applying these skills in their daily life.

\section{Regulating blood glucose levels}

Children with diabetes need to compensate for their insufficient or nonexistent production of insulin. They must monitor their blood glucose levels and inject insulin to avoid high and low glucose levels, which can, respectively, lead to cluttering of the blood veins and triggering a comatose reaction. The process of monitoring glucose and injecting insulin takes place throughout the day and is mainly concentrated around meals. A healthy value for a child is a glucose level between $3.5 \mathrm{mmol} / \mathrm{L}$ and $10 \mathrm{mmol} / \mathrm{L}$.

\section{Avoiding complications}

Maintaining a healthy $\mathrm{HbA}_{1 \mathrm{c}}$ helps to avoid diabetes complications related to the vasculature in later years, such as cardiovascular disease, visual impairment, kidney damage, and nerve damage. $\mathrm{HbA}_{1 \mathrm{c}}$ refers to the percentage of glucose bound to hemoglobin on red blood cells. It gives an indication of the average blood glucose levels of the past 2-3 months. A healthy $\mathrm{HbA}_{1 \mathrm{c}}$ level ranges from $7.6 \mathrm{mmol} / \mathrm{L}$ to $9.0 \mathrm{mmol} / \mathrm{L}$.

\section{Nutrition}

In addition to monitoring blood glucose and injecting insulin, the interviewed care providers emphasized that nutrition is an important component of diabetes self-management. One care provider (a dietician) explained: "In the past, it was common to follow a strict diet, but today a child can eat the same - healthy - nutrition as a child without diabetes." The emphasis has shifted from regulation of the quantity and type of food under a fixed schedule to the amount and type of insulin to inject. This gives the children more freedom in their choice of food and helps them gain insight into how to deal with practical changes in nutrition.

\section{Care tasks of formal and informal care providers \\ Diabetes care team}

In The Netherlands, diabetes care is provided on a policlinic basis by a diabetes care team. This "formal" care team consists of at least one pediatric nurse, a diabetic nurse, 
a dietician, and a psychologist. Shortly after diagnosis, contact between the team, child, and parents is intensive, but levels out later on. Follow-up visits take place every 3 months in the form of a carousel consultation, ie, a visit during which the child meets with personnel from different disciplines within the team.

\section{Encouraging self-management}

In the course of the interviews it became apparent that, during the clinic consultation, the focus of the care team is on encouraging the child to undertake self-management. One caregiver (a pediatrician) indicated: "Communication about the illness and its management is firstly directed to the child." The key person in the diabetes team is the diabetes nurse and after diagnosis, he or she provides the child (and parents) with an intensive course on diabetes. During the course, the children acquire the basic knowledge and skills to self-manage the illness. Education and training continues over time and deals with new experiences in the life of the child, such as participating in sport, going on holiday, having a party, and celebrating Christmas.

\section{Changing behavior}

The formal care providers indicated that children aged 8-12 years are old enough to be addressed directly and to discuss important illness and management topics. One caregiver (a pediatrician) explained: "Children at the age of 8-12 can be persuaded to change their behavior by applying rewarding mechanisms." If children are reluctant to cooperate, the diabetes team member will direct the communication at the parents. They also use motivational interviewing techniques to cope with the children's resistance. This client-centered approach, developed by Rollnick et al, aims at increasing intrinsic motivation to change behavior by exploring and resolving ambivalence on the part of the patient. ${ }^{19}$

\section{Parenting}

At home, parents or guardians play a pivotal role in the child's self-management. Due to this role, they in fact are informal care providers. Parents are involved in monitoring blood glucose levels, counting carbohydrate intake, injecting insulin, coping with unusual occasions, and recognizing symptoms of hypoglycemia and hyperglycemia. As a result of parental support, children aged 8-12 years usually have few problems with their diabetes management.

\section{Developing autonomy and empowering}

The formal care providers indicated that, as children reach puberty, they develop a need for autonomy and may rebel against their parents. One diabetes nurse reported, "Puberty comes at the cost of their diabetes self-management." To prevent this, children need to be given more room to take responsibility for their illness and to take this responsibility early on and in a stepwise manner. The other diabetes nurse emphasized: "If a child is ready to inject insulin, it is important that parents indeed hand over this responsibility to the child. A feeling of empowerment, control, and being open about having diabetes are important for obtaining acceptance of the diabetes."

Motivating the child to take responsibility early on can be accomplished by showing its benefits, using operant conditioning (ie, the child modifies their behavior due to the association of goal behavior with a stimulus, such as positive reinforcement) and automating the behavior (ie, developing a habit) over time. With each step, the child gains more control over diabetes.

\section{Personal characteristics}

The way children cope with their illness depends on their age as well as their emotional and cognitive development. As the pediatrician commented, "Younger children mainly make use of behavioral strategies, such as venting feelings, whereas older children apply cognitive strategies, such as giving structure to the illness." High agreeableness, high conscientiousness, and low neuroticism in a child are related to better glycemic control in childhood. However, perfectionist children can become frustrated when entering puberty, because hormonal fluctuations negatively influence glycemic control.

\section{Qualitative evaluation and implications for future directions}

\section{Future directions}

To stimulate self-management by children with diabetes, the care providers supplied the following directions. A caregiver (pediatrician) noted: "First, provide more attention to operant conditioning by positive reinforcement, as this is a key element in teaching the child to be responsible for and to take control of the diabetes. Second, when supporting children with diabetes, care providers and parents need to attend more to their emotions." Biologically, diabetes can have a negative impact on a child's mental well-being and this needs to be carefully monitored. Finally, one of the diabetes nurses commented that "Education can help a child understand how diabetes works in theory, but is insufficient to cope with diabetes in daily life." This requires practical training for both everyday and uncommon but impacting situations. 


\section{Diabetes self-management}

\section{Self-management activities}

The children interviewed indicated that they measured their glucose levels, took their medication, injected insulin, monitored their food intake and physical exercise, and controlled their carbohydrate intake. They also took their glucometers to school. Finally, they maintained their insulin pumps (ie, replacing the battery and reservoir) and replaced pens regularly.

\section{Knowledge}

When asked if they "know what to do during an unexpected situation" (eg, if their glucose level is unexpectedly low or high), seven children responded positively. They had received information from their care providers and parents, and generally felt that they had enough knowledge to cope with the situation. Moreover, they felt they had the skills to apply this knowledge. Child 4 explained: "When I feel that I have a low glucose level, I take a sweet with dextrose or I eat some gingerbread." However, when faced with uncommon and irregular situations, the children felt a lack of the required skills. By way of example, child 6 indicated "Sometimes I find it difficult to decide what to do when I do not feel well, but I have a glucose level of six." In this case, depending on the situation, the glucose level may be increasing (hyperglycemia) or decreasing (hypoglycemia), each requiring a different type of treatment.

\section{Medical consultations}

The children had both positive and negative experiences about medical consultations for their diabetes. Three children liked to go to the hospital. They received a gift, learned more about their diabetes, enjoyed doing a diabetes quiz, and did not have to go to school that day. Child 2 felt that the doctors and diabetes nurses were friendly. The children reported: "I like to go to the doctor, as long as it is not during class" (child 1) and "Every time I learn more about diabetes, handling my diabetes improves" (child 8).

Four children felt that the medical consultations were boring and difficult to understand. They did not like missing classes and felt they needed to stay too long, or felt that the doctor asked a lot of questions when they did not like to talk about their diabetes. Children expressed the following: "Sometimes I do not understand everything the doctor explains and it is boring" (child 1) and "When we go to the diabetes nurse I have to talk about my diabetes and she asks many questions; I do not like that" (child 3).

\section{Performing self-management}

The children perceived self-management as both positive and negative. Positive aspects related to special treatment and enthusiasm about developing new skills: "When we go to the doctor, I do not have to go to school" (child 4) and "Handling my diabetes is improving" (child 5). The negative aspects related to being perceived as different from peers and feeling constrained: "It is difficult when I do not feel well and I have to go inside while the others continue playing outside" (child 7) and "I cannot eat everything I would like" (child 9).

\section{Diabetes and important life domains Diabetes events}

All children enjoyed attending a camp or visiting a one-day event specifically for children with diabetes. They felt it was special to be with so many children suffering from diabetes. They also appreciated not needing to talk about their diabetes during these days: "I do not have to talk about my diabetes, we just understand each other" (child 4). The children also reported that, during these events, they could learn from other children about their diabetes and that they helped each other with practical problems (eg, controlling their glucose levels or controlling their carbohydrate intake). Child 5 remarked: "We help each other with counting carbohydrates." Child 8 said that he liked to attend "because everyone has diabetes and nobody bullies me about my diabetes."

\section{Going outdoors}

The children interviewed reported some negative experiences when performing self-management while playing outside, in that they had to perform certain activities which others do not: "I don't like to check my glucose level when I am playing outside; I am the only one who has to do this" (child 1). Also, they experienced physical constraints due to the self-management tools they use: "When I fall on my insulin pump, it hurts" (child 9).

\section{Sports}

The children sometimes experienced problems while playing sport, ie, not feeling well, having to control their glucose level continuously, or having practical problems with their insulin pump. One child commented, "When my glucose level is too low, I need rest" (child 7). Others stated that they had figured out how to cope with their illness: "I have no problems with doing sport. When I do not feel well, I eat something" (child 2) and "I control my glucose level before I go to the training ground and afterwards" (child 8). 


\section{Diabetes and quality of life: social, physical, and mental well-being}

Social support

The children received support from their parents (mostly their mother) and were all positive about this. They reported that their parents helped them with the more challenging aspects of diabetes management (eg, injecting insulin or controlling their carbohydrate intake), joined them on school trips, went with them to the hospital, and reminded them that they had to control their glucose level. Children said: "Sometimes they remind me that I have to control my glucose level" (child 1), "I do not have to do everything alone" (child 2), and "They take care of me and help me when I have to inject insulin" (child 5).

\section{Siblings}

The eight children with siblings indicated that their siblings supported them with their diabetes. The older siblings helped them when their parents were away, eg, by injecting insulin and controlling their glucose levels. Older siblings provided comfort when they did not feel well and helped them with controlling their carbohydrate intake. These children were positive overall about this support.

\section{Family}

Four children indicated that they also received support from other family members, eg, aunt, grandfather, or grandmother. They helped with measuring glucose levels and attending to high or low glucose levels. Notably, when family members looked after the child while the parents were away, the children's level of self-support increased. Child 4 expressed: "When I am at home, my mother reminds me that I have to measure my glucose level; my grandmother didn't, so when I am at my grandmother for the weekend, I can do it more by myself."

\section{Friends with diabetes}

All the children interviewed were positive about having a friend with diabetes. Children having a friend with diabetes said that they just played with each other instead of talking about having diabetes. Child 3 said that she sometimes talked with her diabetic friends about having diabetes and child 9 said that they gave each other practical support. Children who did not have a friend with diabetes indicated they would like to have one. They felt that they could learn about diabetes from each other and not be lonely with diabetes: "I would like to have a friend who also has diabetes, so I am not the only one who has to prick myself all the time to measure my glucose level" (child 2).

\section{Physical well-being}

With regard to physical well-being, the majority of the children experienced several symptoms during a high or low glucose level. When they had a high glucose level, they were thirsty, urinated frequently, were hyperactive, listless, and irritable, had a headache, or had a "sinking" feeling. When they had a low glucose level, they experienced hunger, dizziness, fatigue, listlessness, irritation, or headache.

\section{Mental well-being}

The children reported different experiences with regard to mental well-being. Some children worried about their diabetes. They worried about having a too low or too high glucose level and about what they had to do in unexpected situations, or about the implications of irregular glucose levels: "Sometimes I worry about having a high glucose level and that I have to stay in the hospital again" (child 2). Child 1 stated that he had worried shortly after being diagnosed with diabetes, but at the time of the interview he did not worry any more.

Some children stated that they were unhappy due to their diabetes or even hated their illness. They did not like to go to the hospital and talk about their diabetes. They also did not like to control their glucose level and to be treated differently. Children said: "I do not like to go to the hospital all the time" (child 5) and "I do not like it that I always have to control my glucose level" (child 9). Other children said that they were not unhappy due to their diabetes. They do not think about their diabetes or they felt the same as other children and could handle their diabetes: "I can do the same as other children, I just have diabetes" (child 3).

Children 4 and 7 said that they felt insecure because of their diabetes. They were insecure about having a too high or too low glucose level, or that their classmates would bully them about their diabetes. Other children said that they did not feel that way. They did not find it difficult to talk about diabetes, and their classmates did not make negative comments about diabetes. Moreover, some said that they did not care about how their peers thought about them. Child 3 said: "I am not insecure about my diabetes; I get support from my friends when I do not feel well."

\section{Diabetes at school}

\section{Role of the teacher}

The children reported difficulty coping with diabetes at school. In general, teachers supported the children when 
they had a high or low glucose level, notified the children when they could eat a snack, reminded them to measure their glucose levels, and supported them when they got a treat from a classmate. However, the teacher did not necessarily know how to deal with diabetes in the event of uncommon and irregular situations and needed to summon parental help. This may stigmatize the child. During school trips, regular self-management routines do not apply and self-management becomes more challenging.

\section{Role of classmates}

All children in our study gave a presentation about diabetes in class. They appreciated their classmates' awareness, although not all classmates understood what diabetes specifically implies. Half of the children interviewed indicated that they received support from their classmates. Classmates accompanied them when they were not feeling well, helped to measure their blood glucose level, inquired about their blood glucose level, and warned them when they were looking pale.

\section{Practical problems at school}

The children experienced practical problems at school due to their diabetes. The children have to go to the hospital and therefore miss class, cannot eat treats while other classmates can, and miss tests when they do not feel well (eg, writing is challenging when they are trembling). Also, they have to control their glucose level during class, which is distracting.

\section{Children with diabetes and their parents}

Issues upon which three or more children and their parents (as informal care givers) had different perspectives included the following: "Being satisfied with diabetes treatment", "Having physical troubles due to diabetes", and "Experiencing problems at school due to diabetes". The children did not like to go to hospital, because they felt it was boring and that the visits were too long. In contrast, their parents felt that their children were overall positive about the diabetes care they received. The children also reported that they experienced physical problems due to their diabetes, such as thirst, frequent urination, hunger, dizziness, and fatigue, whereas the parents thought their children did not. Finally, the children said that they sometimes had problems at school, due to their diabetes, such as not being able to inject insulin, whereas their parents said they did not.

\section{Discussion}

In order to study how diabetes self-management is organized for children and how children experience their illness and its management in regard to their quality of life, we conducted semistructured interviews with diabetes care providers and children aged 8-12 years with diabetes in The Netherlands. Parents were also surveyed about their child's diabetes and coping with the illness. The results provide guidance for developing robot support functioning and user requirements.

\section{Children's diabetes self-management}

In general, children aged 8-12 years did not experience significant problems with their diabetes self-management. At this age, parents play a leading role in the execution of most aspects of diabetes management. In line with the research reported by Dedding et al, it is recommended that children become more self-supporting, preferably before they reach puberty. ${ }^{15}$ Therefore, care providers consider that it is important for children to become more autonomous in their self-management at an earlier age. Although it is emphasized that increasing autonomy has to be in line with the cognitive and emotional development of the child, children can be given more responsibility than currently is the case.

Increasing children's autonomy can be realized by emphasizing benefits, operant conditioning, and habit formation. Also, in addition to education, it is beneficial to provide hands-on training to be able to deal with uncommon and irregular situations. This helps children to develop relevant skills and become more confident, as well as mitigating their worries and insecurities. Overall, it is advised to focus on the personal characteristics of the child. As an example, age and personality are known to lead to variation in the choice of coping strategy and its effect. One can select a relevant type of support, eg, one that is more directive for younger children and one that is more coaching for older children.

When providing education and training, it is beneficial to relate to the children's more important life domains and their quality of life. The children indicated that they welcomed friends with diabetes and support from their social environment. Empathy for their situation and support from their peers was greatly appreciated. For example, the children enjoyed attending camp and being with peers. Training could be provided in these group settings, whereby uncommon and irregular situations can be simulated. Another option is to provide self-management support sessions with groups of children at the clinic and train them in functional activities which can be easily transferred to the real-life setting. ${ }^{19}$ Both training options enable them to improve their self-management skills in a safe and uniform setting. Ultimately, the child feels no different from other children, 
and wants to be addressed and appreciated as would any other young individual.

These results provide the building blocks to help children with diabetes to become empowered. They can be categorized as follows: ${ }^{21}$

- Having insight into diabetes; through education provided at the clinic, children become knowledgeable about their diabetes, and can monitor their glucose levels regularly and be aware of the role of nutrition

- Making informed decisions, whereby as children grow older, they make increasingly informed decisions about the best course of action, not only basing their choices on the best medical outcome, but also on its impact on important life domains

- Developing self-management skills and habits; theory needs to be transferred into practice, and training helps children to develop self-management skills, including in irregular situations; through operant conditioning, selfmanagement can become a habit

- Managing social influences, whereby various persons in the child's social sphere influence diabetes management (both positive, eg, motivation, and negative, eg, bullying), and the child needs to manage these different influences.

\section{Perception of diabetes self-management}

The results of our interviews with children showed that they accepted diabetes as a part of their lives. They did not want to be seen as patients, but as regular children. By way of example, children appreciated the support of their parents, siblings, and, in some cases, other people in their social environment (eg, grandparents), but not when it was defined as "care". Also, although diabetes was well managed overall, the children experienced difficulties in unusual situations, such as when on holiday. Moreover, having diabetes comes at the cost of the child's mental well-being (eg, insecurity, fear, and worry) and physical well-being (eg, listlessness and tiredness). With regard to social well-being, the children enjoyed attending diabetes camps and having friends with diabetes, due to a common understanding of their condition. Accordingly, diabetes care needs to focus on both the physiological and psychosocial state of the child. ${ }^{22}$ Finally, parents are not always fully aware of how children experience their illness and management.

The care providers interviewed in this study tended to perceive self-management from a more medical (as opposed to psychosocial) point of view. They indicated that, for glucose regulation, children need to become diabetes experts and thus need to watch their nutrition, monitor glucose levels, and inject insulin accordingly. In practice, children indeed perform these self-management activities, but they are also faced with the impact of self-management on important life domains and quality of life. As a result, children may choose suboptimal self-management to maintain their quality of life. For example, in regard to social well-being, self-management can lead to being stigmatized, and children may choose not to prick insulin at school before a meal because of peer pressure.

Moreover, care provider support focuses on educating the child to become more autonomous in self-managing their illness. In turn, children feel they know enough about the illness and its management, but struggle when handling uncommon and irregular situations. Notably, children have worries and insecurities about these types of situations, ie, not being able to cope with them affects their mental well-being. Moreover, children indicate that although support from care providers contributes to their self-management, going to the hospital can be boring, tedious, and painful, and the instructions given are not always clear.

When we look at the differences between the views of children with diabetes and those of their parents in regard to self-management, two issues emerge. First, at the age of 8-12 years, parents play a leading role in the management of the child, which recedes when children reach puberty. In this phase of life, children develop an increasing need for autonomy and are faced with new developments, such as hormonal changes. Because children lack the skills to cope with uncommon and irregular situations, their selfmanagement can lead to worsening of their diabetes, as reported by Laffel et al. ${ }^{23}$

Second, parents are not always fully aware of how children experience their illness and the impact of self-management on their quality of life. In regard to satisfaction with diabetes treatment, physical well-being, and experiencing problems at school due to diabetes, the parents interviewed had a more positive view of how their children experienced these issues than how children experienced them themselves.

It is challenging for children to regulate their glucose levels at school. In turn, diabetes places constraints on school performance, which is considered an important life domain. Teachers generally offer help but are not experts and are not always capable of supporting the child adequately. This is not just an issue in The Netherlands, given the international studies showing that school personnel have an inadequate understanding of diabetes. ${ }^{24,25}$ 


\section{Study limitations and future research}

In this study, we focused on the Dutch approach to diabetes health care, which may differ from approaches used in other countries. However, self-management is used internationally. ${ }^{26}$ In the ALIZ-E project, similar interviews take place with other involved partners (eg, in Italy, Germany, and the UK), which will elicit more insights into similarities and differences. With regard to the children interviewed, the pool of participants in our study was relatively small and homogenous. Although in qualitative research nine participants can provide good insights, it is preferable to have a larger group. Overall, the children had good metabolic control and were similar in cultural background (ie, native Dutch) and family setting (ie, from predominantly two-parent, two-children families). We can assume that the need for self-management support is somewhat greater in children, who experience more extreme health problems due to their diabetes or come from immigrant families.

\section{Social robots supporting diabetes self-management}

Our study corresponds to the findings of the Latitude study in which children were shown to be able to imagine robots as a social companion that can entertain, motivate, and empower them in various contexts. ${ }^{12}$ From the results of our study, a number of functions for such social robots could be devised to empower children and take account of the individual context. These functions can be categorized according to the four empowerment aspects discussed in the section on Children's diabetes self-management: ${ }^{21}$

- Gaining insight into one's own health condition: efficient and attractive learning to become a "diabetes expert", eg, via a quiz; clarifying information provided by the caregivers through movie, clips, or quizzes on diabetes

- Making informed decisions, eg, helping the child coping with unexpected or novel situations

- Developing self-management skills and habits, eg, supporting glucose regulation through reminders and monitoring; reminding the child to measure glucose levels and keep track of carbohydrate intake, ie, through electronic diary or sensoring; supporting processing information about type 1 diabetes, eg, a decision aid

- Managing the social environment, eg, in challenging situations, reassuring and directing the child towards persons in the social environment (parents, teacher, siblings), or acting as a buddy; children are positive about having a friend with diabetes, and in the study by Funnell et al it was found that peers can provide the psychosocial and behavioral support needed for long-term self-management of diabetes. ${ }^{27}$

In regard to user requirements, the content provided by the robot needs to be consistent with that provided by health care professionals and parents. Also, the behavior of the robot should be in line with the self-management support activities of key persons in the child's social environment (ie, parents, siblings). For example, the robot could help parents to monitor how their children experience their illness and different aspects of its management in regard to mental and physical well-being. Another important requirement is that interaction with the robot should not lead to stigmatization. It should not overly focus on diabetes (eg, child and robot play games together or watch films or the robot helps with homework) and attend to both the positive and negative experiences and emotions of the child. Concerning the latter, the robot needs to be aware of the child's important life domains (eg, school and sport) and emotions (eg, worries, unhappiness, insecurity), which can be assessed from the child's physical state and verbal utterances. When these user requirements are met, the robot could contribute in a personalized way to the child's long-term self-management skills and habits, and minimize the impact of diabetes on both health and quality of life.

\section{Acknowledgments}

This research was partly funded by the EU FP7 ALIZ-E project. We would like to thank the collaborating hospitals and medical centers, ie, Franciscus Ziekenhuis Roosendaal, and Diabeter Martini Ziekenhuis, Deventer Ziekenhuis, Medisch Spectrum Twente, Diabeter, and Kinder Diabetes Centrum Nijmegen. Finally, we would like to acknowledge the valuable input of the children with diabetes who participated in this study, along with that of their parents.

\section{Disclosure}

The author reports no conflicts of interest in this work.

\section{References}

1. An-Hsuan C, Chyi-Feng J, San-Ging S, Bee-Horng L. Self-efficacy affects blood sugar control among adolescents with type 1 diabetes mellitus. J Formos Med Assoc. 2010;109:503-510.

2. Hood KK, Peterson CM, Rohand JM, Drotar D. Association between adherence and glycemic control in pediatric type I diabetes: a meta-analysis. Pediatrics. 2009;124:e1171-e1179.

3. Levine BS, Anderson BJ, Butler DA, Antisdel JF, Brackett J, Laffel LMB. Predictors of glycemic control and short-term adverse outcomes in youth with type 1 diabetes. J Pediatr. 2001;139:197-203.

4. Lynne S, Schilling RN, Grey M, Knafl KA. The concept of selfmanagement of type 1 children and adolescents: an evolutionary concept analysis. J Adv Nurs. 2002;37:87-99. 
5. Hoey H, Aanstoot HJ, Chiarelli F, Daneman D, Danne T, Dorchy H. Good metabolic control is associated with better quality of life in 2,101 adolescents with type 1 diabetes. Diabetes Care. 2001;24:1923-1928.

6. Kalyva E, Malakonaki E, Eiser C, Mamoulakis D. Health-related quality of life (HRQoL) of children with type 1 diabetes mellitus (T1DM): self and parental perceptions. Pediatr Diabetes. 2011;12:34-40.

7. Vanelli M, Chiarelli F, Chiari G, Tumini S. Relationship between metabolic control and quality of life in adolescents with type 1 diabetes: report from two Italian centres for the management of diabetes in childhood. Acta Biomed. 2003;74:13-17.

8. Wagner VM, Muller-Godeffroy E, von Sengbusch S, Hager S, Thyen U, Age, metabolic control and type of insulin regime influences healthrelated quality of life in children and adolescents with type 1 diabetes mellitus. Eur J Pediatr. 2005;164:491-496.

9. Soltesz G, Patterson CC, Dahlquist G. Worldwide childhood type 1 diabetes incidence - what can we learn from epidemiology? Pediatr Diabetes. 2007;8:6-14.

10. Dedding C, Reis R, Ramaker C, Wolf B. What do children think about their diabetes? Ned Tijds Diabetologie. 2004;2:86-89. Dutch.

11. Snoek FJ, Skinner TC. Psychology in Diabetes Care. Chichester, UK: John Wiley \& Sons; 2007.

12. Latitude. Robots at School. Available at: http://bit.ly/robotstudy. Accessed May 24, 2012

13. Janssen JB, Wal CC van der, Neerincx MA, Looije R. Motivating children to learn arithmetic with an adaptive robot game. Presented at the Third International Conference on Social Robotics, September 24-25, 2011, Amsterdam, The Netherlands.

14. Blanson Henkemans OA, Van Der Mast CAPG, Neerincx MA, Lindenberg J, Van Der Boog PJM, Zwetsloot-Schonk JHM. An online lifestyle diary with a persuasive computer assistant providing feedback on self-management. Technol Health Care. 2009;17:253-267.

15. Dedding C. Sharing Power and Powerlessness: Children's Participation in (daily) Diabetes Care. Amsterdam, The Netherlands: University of Amsterdam; 2009. Dutch.
16. Blanson Henkemans OA, Molema JJW, Franck EJH, Otten W. Self-management as Labor-saving Health Care Innovation Report $K v L / P \& Z$ 2010.017. Leiden, The Netherlands: TNO; 2010. Dutch.

17. Wit M, Snoek FJ. DAWN youth: international insights and strategies toward a person-centered care model for young people with diabetes. Pediatr Diabetes. 2009;10:15-20.

18. Wake M, Hesketh K, Cameron F. The child health questionnaire in children with diabetes: cross-sectional survey of parent and adolescentreported functional health status. Diabet Med. 2000;17:700-707.

19. Rollnick S, Miller WR, Butler C. Motivational Interviewing in Health Care: Helping Patients Change Behavior. New York, NY: Guilford Press; 2008.

20. Schmidt RA, Wrisberg CA. Motor Learning and Performance. Champaign, IL: Human Kinetics; 2004.

21. Blanson Henkemans OA, Molema JJW, Alpay LL, et al. Innovations for self-care: development of services and technology for sustainable care. TSG. 2010;3:112-116. Dutch.

22. Wit M, Snoek FJ. Depressive symptoms and unmet psychological needs of Dutch youth with type 1 diabetes: results of a web-survey. Pediatr Diabetes. 2011;12:172-176.

23. Laffel LM, Connell A, Vangsness L, Goebel-Fabbri A, Mansfield A, Anderson BJ. General quality of life in youth with type 1 diabetes: relationship to patient management and diabetes-specific family conflict. Diabetes Care. 2003;26:3067-3073.

24. American Diabetes Association. Diabetes care in the school and day care setting. Diabetes Care. 2011;34:S70-S74.

25. Hanas R. Type 1 Diabetes in Children, Adolescents and Young Adults. London, UK: Class Publishing Ltd; 2007.

26. American Diabetes Association. Standards of medical care in diabetes, 2011. Diabetes Care. 2011;34:S11-S61.

27. Funnell MM. Peer-based behavioural strategies to improve chronic disease self-management and clinical outcomes: evidence, logistics, evaluation, considerations and needs for further research. Fam Pract 2010;27:i17-i22.
Patient Intelligence

\section{Publish your work in this journal}

Patient Intelligence is an international, peer-reviewed, open access journal that characterizes and measures the central role of patient behavior and intention in optimizing healthcare management in all areas of disease and complaint types. An improved understanding of patient intelligence coupled with predictive analysis helps an organization contribute more effectively to achieving better outcomes.

\section{Dovepress}

The journal is characterized by the rapid reporting of reviews, original research, methodologies, analytics, modeling, clinical studies and patient surveys across all disease areas. The manuscript management system is completely online and includes a very quick and fair peer-review system. Visit http://www.dovepress.com/ testimonials.php to read real quotes from published authors. 